\title{
Índices de qualidade configuracional urbana O caso do Distrito Federal, Brasil
}

\author{
Rômulo Ribeiro. Universidade de Brasília, Brasília, Brasil. \\ Frederico Holanda. Universidade de Brasília, Brasília, Brasil. \\ Juliana Coelbo. Universidade de Brasília, Brasília, Brasil.
}

\begin{abstract}
RESUMO | $\mathrm{Na}$ busca da compreensão e análise urbana muito se tem avançado, com o desenvolvimento de índices e indicadores que expressam características e comportamentos de fragmentos da cidade. Este estudo procura contribuir para preencher a lacuna que ainda existe nesse âmbito, com uma proposta de "costurar" importantes índices urbanos, levantados a partir de grandes dimensões configuracionais, de forma a se compor uma nova visão da cidade. O objeto de estudo é o Distrito Federal, capital do Brasil, que, devido a sua configuração segmentada, torna-se um excelente experimento, pois cada segmento urbano tem características intrínsecas. As dimensões selecionadas revelam de forma genérica que o centro urbano do Distrito Federal, composto pelo Plano Piloto e suas imediações, apresenta melhores resultados para todos os índices levantados, enquanto maior o afastamento do centro piores se tornam as condições de vida. Apesar dessa tendência, muitas cidades periféricas, que têm estigma de baixa condição de vida, apresentam bons resultados em determinados aspectos.
\end{abstract}

PALAVRAS-CHAVE | expansão urbana, morfologia urbana, distribuição espacial.

ABSTRACT | There has been great progress in the search for understanding and analysis of urban systems, especially with the development of indices and indicators that express the characteristics and behavior of fragments of the city. This study seeks to fill the gaps still persisting in that field with a proposal to "stitch" important urban indices, surveyed from large configurational dimension, as a way to compose a new vision of the city. The object of study is the Federal District, Brazil's capital, because of its segmented configuration, is a great experiment, because each segment of the city has intrinsic characteristics. The selected dimensions show in a general way that the urban center of the Federal District, composed of the Pilot Plan and its surroundings, shows better results for all indices surveyed, while worst living conditions are found further away from the center become the. Despite this trend, many peripheral cities, which have the stigma of low status, have good results in certain respects.

KEY WORDS | urban sprawl, urban morphology, spatial distribution.

Recibido el 15 de agosto de 2010, aprobado el 4 de abril de 2011.

E-mail: Rômulo Ribeiro, rjcribeiro@unb.br|Frederico Holanda, fredholanda44@gmail.com |Juliana Coelho, jujucoelho@gmail.com. 


\section{Introdução}

A cidade como estrutura moldada pela população que nela habita, pois são os processos sociais que a definem, incluídos ou não procedimentos formais de planejamento, necessita de monitoramento constante para que se possa compreender sua dinâmica e, a partir daí, elaborar planos e definir ações que também sejam dinâmicos, capazes de se adaptarem às novas situações, bem como direcioná-las a fim de que a cidade melhore seu desempenho.

Nos últimos cinqüenta anos, as cidades têm crescido e se desenvolvido numa velocidade muito grande. Praticamente em todo o mundo houve uma inversão entre o número de habitantes rurais e urbanos, sendo que esses últimos ultrapassaram muito, em número, a população rural. Segundo o Censo Demográfico de 2010, $84,4 \%$ da população brasileira localiza-se em centros urbanos (Instituto Brasileiro de Geografia e Estatística [IBGE], 2011).

Devido a essa situação, que tende a se tornar cada vez mais crítica, as cidades têm crescido de forma rápida com pouco ou nenhum controle. Isso leva a geração de tensões urbanas de diversos tipos, bem como a um aumento dos custos de manutenção dessa realidade. O poder público cada vez deve gastar mais para tentar suprir as demandas que surgem com o crescimento urbano.

Essas altas concentrações populacionais nas cidades podem levar a uma reformulação da circulação e do próprio desenho urbano, o que faz com que se comprometa a qualidade de vida e qualidade ambiental urbana. Isso ocorre, entre outros fatores, em função da demanda por habitação ser bem maior que a oferta, o que leva à população, principalmente a de menor renda, a ocupar regiões cada vez mais distantes do centro da cidade. Por tratar-se, muitas vezes, de ocupações irregulares, pode-se verificar que vários fatores relacionados à qualidade de vida e qualidade ambiental não são considerados.

Essa qualidade de vida tem sido medida de maneira incompleta, uma vez que é realizada de forma segmentada, e esse é o ponto central desta proposta: falta uma "costura" de índices espaciais além dos tradicionais a-espaciais de forma a permitir uma visão diferenciada e mais próxima da realidade. Comumente são encontradas na literatura diversas formas de se mensurar as dimensões urbanas, quase sempre cada uma dessas dimensões é estudada e avaliada de maneira isolada. Essa visão segmentada não permite que a cidade seja compreendida de forma mais realista e abrangente.

Autores como Hillier e Hanson (1984), Bertaud e Malpezzi (1999; 2003), Jenk e Burgess (2000), Holanda (2001; 2002; 2003), Ribeiro e Holanda (2005), Ribeiro (2008) têm mostrado que a cidade influencia no comportamento de sua população, bem com essa população influencia na organização espacial da cidade, numa relação mútua e constante. Em certos casos, é possível caracterizar verdadeiros guetos urbanos, nos quais pessoas com características socioeconômico-culturais semelhantes tendem a se concentrar espacialmente.

O Distrito Federal (DF) é uma unidade da federação brasileira com uma característica político-administrativa peculiar: não pode ser dividido em municípios. Por isso, acumula competências de Estado e de município, possui uma Câmara Le- 
gislativa e um Governo do Distrito Federal. Possui trinta Regiões Administrativas (RAs) que na hierarquia administrativa estão subordinadas à Secretaria de Estado de Governo. Algumas dessas cidades, que compõem as RAs, já existiam antes do início da construção de Brasília, como Brazlândia e Planaltina, e outras se formaram durante a construção, como Núcleo Bandeirante e Taguatinga. As pesquisas do Instituto Brasileiro de Geografia e Estatística consideram um único município no Distrito Federal: Brasília. Esse tratamento dado ao DF por vezes prejudica as análises, pois mascara informações que, dentro do DF, são bastante distintas e quando se considera apenas o todo se subestima essas variações, normalmente obscurecendo dados relativos às situações sociais mais críticas.

A escolha por utilizar a base espacial definida pelo Censo Demográfico de 2000 foi em função da possibilidade de atualização periódica das variáveis. Como o Censo brasileiro é realizado a cada 10 anos, pode-se traçar a evolução urbana, a partir de dados coletados de forma padronizada. Além disso, como os métodos desenvolvidos usam uma base de dados oficial, eles podem ser aplicados a outras cidades do país, o que torna a proposta aqui desenvolvida acessível a outras instâncias governamentais do Brasil.

A ênfase deste trabalho está na análise integrada de índices morfológicos de dispersão urbana, acessibilidade viária e ociosidade per capita por meio de setores censitários, uma vez que essas unidades são levantadas pelo IBGE a cada 10 anos e são as que apresentam informações mais desagregadas. As categorias analíticas foram definidas a partir da concentração e dispersão urbana, baseadas nas distâncias de deslocamentos da população ao Centro de Comércio e Serviços (CCS) (mais conhecido como CBD - Central Bussiness District). Os resultados obtidos foram normalizados para uma escala fixa, de forma a facilitar a comparação entre diferentes cidades, o que facilita a interpretação e análise dos resultados (Ribeiro, 2008).

Juntas, as variáveis contribuem para uma identificação mais abrangente da configuração de uma cidade, do que se tomadas isoladamente, como é o caso dos estudos que serão referidos.

\section{Características do DF}

A formação do espaço urbano de Brasília contém especificidades do contexto de sua construção, mas possui também traços característicos dos processos sociais que fundamentam a estruturação interna das demais cidades brasileiras. Assim, desde a construção de Brasília, iniciou-se uma segregação social dentro do território do Distrito Federal. Os trabalhadores que construíram a cidade não moravam no Plano Piloto (área central), moravam em alojamentos próximos aos canteiros de obra, em invasões e, posteriormente, nas "cidades satélites" (atuais RAs). Para evitar a consolidação das alternativas de moradia, como as invasões, o Estado intervinha por meio da Companhia Urbanizadora da Nova Capital (Novacap), mas não havia um plano que englobasse todo o território do Distrito Federal (Campos, 1998).

Cerca de $9 \%$ da população total do DF mora no Plano Piloto, área central e tombada pela Unesco como patrimônio da Humanidade. Como essa área central concen- 
tra o poder público, cerca de $82 \%$ dos empregos totais (aqui contabilizados os empregos formais e informais) do DF localizam-se ali, o que gera um fluxo unidirecional muito forte nos horários de pico, o que causa grandes congestionamentos viários.

Uma característica marcante da economia do Distrito Federal é a participação da Administração Pública. Desde o início, com a transferência dos servidores federais do Rio de Janeiro para Brasíla, a participação da Administração Pública na economia local é alta. Em 1985, essa participação era de 23,43\% do PIB do DF. Na década de 1990, mesmo com a estagnação do setor público, poucos concursos para provimento de cargos públicos efetivos e congelamento dos salários, reflexos da política neoliberal implantada no país, a participação da Administração Pública no PIB aumentou e em 1999 era de 40,5\% do PIB do Distrito Federal (Secretaria de Desenvolvimento Urbano e Habitação do Distrito Federal [Seduh], 2004). Na década de 2000, principalmente após 2002, a política em relação aos servidores públicos mudou, aconteceram diversos concursos públicos e com isso o número de contratações de servidores públicos federais e locais efetivos aumentou e refletiu na participação desse setor no PIB do DF; em 2006 essa participação foi de 54,84\% (Companhia de Planejamento do Distrito Federal [Codeplan], 2008).

A segunda maior participação no PIB do Distrito Federal é a do setor de Serviços (exclusive a Administração Pública), que em 2006 foi de 38,57\% do PIB. Ao se comparar com o país, a influência do setor de Serviços (inclusive a Administração Pública) em Brasília (93,41\% em 2006) é muito maior que a influência desse setor no PIB nacional (66,6\% em 2007).

A indústria tem pouca participação no PIB, que em 2007 foi de 5,9\%. Dentro desse setor, a maior parte foi referente a construção civil, em 2008, empregava 4,4\% da população ocupada do DF (Departamento Intersindical de Estatística e Estudos Socioeconômicos [Dieese], 2008). A agropecuária representa uma parcela menor ainda, apenas 0,3\% em 2007.

Observa-se que a População em Idade Ativa (PIA) do Distrito Federal teve um aumento considerável de 24,2\%. Esse contingente populacional era de aproximadamente 1,7 milhões de pessoas em 2001 e chegou a mais de 2,1 milhões de pessoas em 2008.

Essa PIA é em maioria feminina e praticamente estável no período entre 2001 e 2008. Em 2001 a PIA do sexo feminino correspondia a 53,8\% do total e em 2008 , a 53,5\%. Em 2001, o número de mulheres em idade ativa era de pouco mais de 920 mil, essa população em 2008 era 1,14 milhões.

Em relação à cor ou raça, onde os dados são relativos a "branco" e "não branco" (que corresponde à pretos e pardos) houve um aumento de "não branco", que em 2001 correspondia a 55,4\% da PIA. Em 2008, esse valor foi de 58,9\%. Ainda não é possível estabelecer uma justificativa a respeito desse aumento, uma das especulações pode ser que a política de cotas para negros da Universidade de Brasília possa, de alguma forma, ter influenciado a população a se declarar como não branca, mas não há nenhuma fundamentação teórica que comprove isso, como mencionado, é apenas uma possível especulação.

A escolaridade é avaliada a partir de quatro faixas, medidas em anos de estudo. Houve um aumento considerável na população com mais de 12 anos de estudo, que 
corresponde a, no mínimo, ter ingressado em um curso do ensino superior. Essa população era de 15\% da PIA em 2001 e em 2008 de 22,5\%, um aumento de 7,5 pontos percentuais. Esse fato ocorreu devido a políticas públicas federais, que nesse período propiciaram o aumento no número de unidades de faculdades e centros universitários, que em 2001 era 48 e em 2008 passaram para 66, um aumento de 37,5\% (Instituto Nacional de Estudos e Pesquisas Educacionais Anísio Teixeira [INEP], 2009). Houve, além da política de cota para negros na Universidade de Brasília e bolsas do Programa Universidade para Todos (ProUNI) que facilitaram o acesso de uma população de mais baixa renda a ingressar no ensino superior, ampliação da capacidade de absorção de alunos pela Universidade de Brasília por meio do Programa de Reestruturação e Expansão das Universidades Federais (Reuni), que permitiu a criação de novos cursos, novos campi e ampliação de alguns cursos já existentes. Em 2001, foram 79.329 matriculados e em 2008, 132.918, um aumento de 67,5\% (INEP, 2009).

A faixa de escolaridade com maior parcela da população é a de 9 a 11 anos de estudo, que são os indivíduos que estariam cursando o ensino médio ou que terminaram mas não ingressaram na universidade, correspondia a 32,9\% da PIA em 2008 , um aumento de 4,1 pontos percentuais. A população que não atingiu o ensino médio, nas faixas de 0 a 4 anos e 5 a 8 anos, diminuiu de $56,2 \%$ para 44,6\%, mas ainda corresponde a uma grande parcela da população.

Quanto à renda total, a avaliação é feita em cinco faixas de renda em relação ao salário mínimo: até um salário mínimo, mais de um até três, mais de três até cinco, mais de cinco até dez e mais de dez. Para a menor faixa de renda houve uma redução de 6,2 pontos percentuais da população em idade ativa, em 2001 eram aproximadamente 199 mil pessoas (22,3\% da PIA) e em 2008 esse número estava por volta de 187 mil (16,2\% da PIA). Mesmo com essa redução, essa faixa de renda abriga a segunda maior parcela da população em idade ativa.

$\mathrm{O}$ exame da taxa de atividade para o perfil etário indica um pequeno aumento para a faixa de 15 a 24 anos (0,6 pontos percentuais) e um pouco maior para as de 25 a 39 anos (1,9 pontos percentuais) e de 40 a 59 anos ( 3 pontos percentuais). A taxa de ocupação para a população de 10 a 14 anos teve uma queda de 1,4 pontos percentuais, passando 3,7\% em 2001 para 2,3\% em 2008. Para a população idosa, acima de 60 anos, a taxa de atividade caiu 0,3 pontos percentuais. A faixa etária com maior taxa de atividade é a 25 a 39 anos com 85,6\% em 2008, seguida pela faixa de 40 a 59 anos (77,2\% em 2008). A taxa de ocupação para a população de 40 a 59 anos e acima de 60 anos é praticamente igual, 96,0\% para o primeiro grupo e $96,3 \%$ para o segundo. Já para os adultos entre 25 e 39 anos, a taxa de ocupação é um pouco menor $(89,6 \%)$ e para a população entre 15 e 24 anos a taxa de ocupação cai para $75,3 \%$. Conclui-se que o desemprego é maior para a população entre 15 e $24 \operatorname{anos}(24,7 \%)$ e para a população entre 25 e 39 anos (10,4\%).

Em relação à escolaridade, a taxa de atividade aumenta com mais anos de estudo, para a população com 12 anos ou mais de estudo chega a 84,8\% em 2008. Para o grupo com estudo entre 9 e 11 anos em 2008 era de 74,1\%, de 51,3\% para o que possui entre cinco e oito anos de estudo e de $37,5 \%$ para o que possui de zero a quatro anos de estudo. Esse último grupo foi o que apresentou maior variação 
na taxa de atividade, diminuindo nove pontos percentuais de 2001 para 2008. A variação para a população com 5 a 8 anos de estudo foi bem menor, de 2,6 pontos percentuais. Para o grupo com 9 a 11 anos de estudo caiu 0,4 pontos percentuais e para quem tem mais de 12 anos de estudo subiu 1,2 pontos percentuais.

A população ocupada subiu em quase todos os grupos analisados, para população que tem de 0 a 4 anos de estudo a taxa de ocupação subiu de 84,3\% em 2001 para $92,7 \%$ em 2008 (aumento de 8,4 pontos percentuais), para a população que tem de 5 a 8 anos de estudo essa taxa passou de $81,2 \%$ para $87,6 \%$ (6,4 pontos percentuais). Para o grupo que possui entre 9 e 11 anos de estudo o aumento foi pequeno, de $84,8 \%$ para $85,8 \%$ (apenas um ponto percentual), é nesse grupo que há a maior taxa de desemprego (14,2\%). A população com mais de 12 anos de estudo foi a única que teve queda na taxa de ocupação, passou de 94,0\% para 92,2\%. É interessante observar que foram nesses dois grupos ( 9 a 11 anos e acima de 12 anos de estudo) que houve o maior aumento na população em idade ativa por faixa de escolaridade. Apesar da menor absorção no mercado de trabalho para o grupo com mais de 12 anos de estudo, a taxa de desemprego ficou em 7,8\%, a segunda menor (a menor foi para a população com até quatro anos de estudo, 7,3\%).

\section{As variáveis - conceitos}

\section{Índice de Dispersão}

Um dos principais elementos da área urbana é a malha viária, seu desenho, hierarquia e materiais, por caracterizar vias arteriais de circulação, que compõem as áreas principais de concentração, tanto veicular quanto de pedestres. A relação de veículos e pedestres com o espaço urbano, principalmente o que se refere à circulação, é importante, pois influencia diretamente em custos e tempo de percurso, além de poder afetar a concentração ou difusão de circulação em determinadas áreas.

Estudos da distribuição espacial da população urbana são numerosos e têm o intuito de melhorar a compreensão da relação ser humano $x$ espaço urbano. São exemplos de trabalhos de análise socioespacial: Hillier e Hanson (1984); Clark (1985); Hillier, Penn, Hanson, Grajewskiet e Xu (1993); Jenks e Burgess (2000); Sposati (2000a; 2000b, ambos citados em Genovez, 2002); Genovez, Caetano e Estrada (2000); Holanda, Passos, Cavalcante, Simões de Bello e Melasso (2001); Holanda (2002; 2003); Genovez (2002); Ribeiro (2003); Ribeiro e Holanda (2005); Ribeiro, Holanda, Romero, Baptista e Bias (2005), além dos trabalhos de análise da distribuição espacial da população realizados por Bertaud e Malpezzi (1999; 2003), Koga (2003) e Ojima (2007). Esses autores, de uma forma ou de outra, trataram a realidade urbana de forma segmentada, pois normalmente estudaram uma única dimensão dessa realidade. Mesmo os autores que trataram mais de uma dimensão fizeram-no de forma separada. A análise urbana deve ser feita de forma sistêmica, a fim de se ter uma visão mais próxima dessa realidade.

Costa e Silva (2007) afirmaram que desigualdades quanto à possibilidade de acesso ao espaço urbano estão na base da segregação socioespacial. A noção de se- 
gregação está ligada a novas formas de ocupação espacial, que implicam segregação inclusive nas pontas do espectro socioeconômico, mas com custos sociais diferenciados. Para Lago (2000), a forma de ocupação como condomínios fechados, horizontais ou verticais, afastados do centro e direcionados para a classe média, tem se expandido cada vez mais. Isso se dá em função do baixo valor da terra, o que viabiliza a aquisição desse espaço pelas classes menos abastadas. $\mathrm{O}$ autor lembra que não apenas o preço da terra é um fator de segregação, mas, especialmente, muros e controle de segurança, que tentam manter afastados todos os que não pertencem àquele lugar.

O modelo brasileiro de cidades caracterizava-se tradicionalmente por ter as classes superiores no centro e quanto menor o poder aquisitivo, mais afastada desse centro a população se localizava. Após a década de 1970, em algumas cidades brasileiras, surgiram ocupações semelhantes ao modelo norte-americano de subúrbios, condomínios para população de alta renda, fechados e afastados do centro. Esse tipo de ocupação é caracterizado como disperso (Reis, 2006) e acarreta diversos custos ao poder público para sua viabilização (rede elétrica, abastecimento de água, coleta de esgoto, asfaltamento, etc.).

Esse tipo de ocupação difusa gera redes descontínuas, desorganizadas, ineficientes e altamente dependentes do carro particular e, no caso do transporte público, implicam sistemas caros e pouco confortáveis (Hasse \& Lathrop, 2003). Isso tem causado um aumento no consumo energético e na quantidade de particulados e gases poluentes oriundos da excessiva circulação veicular.

A dispersão urbana brasileira passa por uma segunda etapa. A primeira foi caracterizada pela periferização e favelização, isto é, populações de baixa renda em busca de acesso ao espaço urbano. Neste segundo momento, há ocupações de áreas cada vez maiores, mas por uma quantidade de população menor. A expansão da malha urbana tem-se dado por população de média e alta renda em busca de qualidade de vida, que se traduz em grandes terrenos em ocupações horizontais (eventualmente verticalizadas) cercadas e que suprem em alguma medida as necessidades básicas dessas populações.

Essas ocupações, conhecidas como condomínios fechados, têm se difundido pelo Brasil. Como se localizam distantes do centro, aumenta-se a dependência de veículos automotores para o deslocamento casa-trabalho-casa. Isso acarreta a cada ano um número maior de veículos automotores nas vias urbanas, o que aumenta a dificuldade de deslocamento, causa engarrafamentos e aumenta a poluição atmosférica.

Esses condomínios também favorecem o processo de segregação socioespacial, pois são unidades socialmente homogêneas, fechadas em si mesmas, empobrecendo o espaço urbano como o espaço da troca por excelência.

Para Costa e Silva (2007), a ocupação urbana dispersa, típica da urbanização brasileira, pode ser bem caracterizada por meio de geoprocessamento, principalmente pela utilização de imagens de satélite, com as quais se poderia acompanhar tal crescimento.

Bertaud e Malpezzi (2003) calcularam a dispersão para 50 áreas urbanas, entre cidades e regiões metropolitanas. Apesar do cálculo comparativo, os resultados não permitem uma análise fácil da dispersão entre as cidades analisadas. Os autores procuraram mensurar a forma das cidades a partir de modelos simples e mostrar que esses podem ser um caminho útil para caracterizar as cidades. 
Não se deve confundir cidades descentralizadas com cidades dispersas. No primeiro caso, as cidades são policêntricas, o que permite a geração de emprego e atração populacional em diferentes pontos da área urbana. Nas cidades dispersas, a população está localizada distante do CCS, principalmente em função dos altos custos de moradia próxima a ele. Com isso, há aumento do custo com transporte e comumente a renda diminui com o aumento da distância ao CCS. Os autores também mostram que esse é o caminho para o mercado imobiliário legal e ilegal, de forma que a organização e a legislação têm profundos efeitos na forma urbana, com implicações diretas quanto ao valor do solo urbano e no sistema de transportes.

O Índice de Dispersão Urbana, proposto por Bertaud e Malpezzi (1999), é um índice de base demográfica para a análise urbana e tem por intuito relacionar, em função da população total, o número de habitantes por setor urbano à distância daqueles setores ao CCS. A partir desse índice é possível analisar o custo urbano, relacionando, entre outras coisas, custo de viagem casa-trabalho-casa.

\section{Índice de Integração}

A Teoria da Sintaxe Espacial é proposta por Bill Hillier e colegas da Bartlett School of Graduate Studies, em Londres, no início da década de 1970. Em 1984, Hillier publicou com Julienne Hanson o livro que reúne inicialmente os principais aspectos da teoria, do método e das técnicas que vêm, desde então, sendo desenvolvidos por eles e por pesquisadores de inúmeros países (Hillier \& Hanson, The social logic of space, 1984). Desde 1997, simpósios internacionais bienais têm reunido esses pesquisadores. No Brasil, eles concentram-se na Universidade Federal do Rio Grande do Norte (UFRN), na Universidade Federal de Pernambuco (UFPE), na Universidade de Brasília (UnB), na Universidade Federal de Santa Catarina (UFSC) e na Universidade Federal do Rio Grande do Sul (UFRGS).

A Teoria de Sintaxe Espacial parte do fato de:

(...) toda sociedade ter grupos espaciais de pessoas, que vivem e se movem em maior proximidade do que outros grupos, e grupos transpaciais baseados na designação de diferentes rótulos a diferentes grupos de indivíduos". Isso levava à afirmação do "principal axioma de toda a teoria sintática do espaço: a organização do espaço é função da forma de solidariedade social; e diferentes formas de solidariedade social são elas próprias baseadas na sociedade como um sistema, tanto espacial como transpacial. (Holanda, 2002, p. 86)

No centro da caracterização da organização do espaço, assim entendida, está a medida de integração. Para calcular a medida para uma cidade, o sistema viário é representado como um grupo de segmentos de reta, que correspondem, aproximadamente, aos eixos das vias. Obtém-se assim o mapa de axialidade, que representa o conjunto de eixos que se cruzam dentro da área estudada. Tal mapa é processado em aplicativos específicos (p.ex. Depthmap, Mindwalk) que revelam quais os eixos mais integrados ao sistema como um todo e quais os mais segregados (em sintaxe, 
as expressões integrado, raso, mais acessível fisicamente, são sinônimas, assim como seus opostos: segregado, profundo, pouco acessível fisicamente). Há duas saídas daqueles aplicativos: uma gráfica e uma numérica. A primeira confere cores aos eixos: as mais "quentes" (tendentes a preto) representam os eixos mais acessíveis; as mais "frias" (tendentes ao branco), os eixos menos acessíveis. A segunda é uma saída numérica: quanto maior a acessibilidade, maiores os valores das linhas.

Pelo mapa processado, pode-se identificar as áreas do sistema que estão mais isoladas (mais segregadas) ou mais integradas, em relação ao sistema todo. Em geral, é nas vias mais integradas que se encontra maior circulação de pessoas e concentração de veículos, comércio e serviços. Isso facilita a avaliação de direções de expansão da cidade, de forma que novas áreas urbanas sejam mais integradas ao sistema, assim como permite inferir medidas para melhorar a integração das áreas segregadas.

Diversos estudos têm sido desenvolvidos no Brasil e no mundo com a utilização desse índice, desde análises urbanas a análises de espaços de edificações. O Índice de Integração tem se mostrado bastante versátil ao trazer informações ligadas principalmente à acessibilidade.

Em um artigo de 1989, Hillier volta a discutir os fundamentos, propósitos e descobertas gerais referentes à Teoria de Sintaxe Espacial, sendo sua tese principal que

(...) se formas sociais são próprias à cidade material, então se requer logicamente que em algum sentido elas sejam um produto da vida material. É o senso comum que o afirma. Cidades de diferentes culturas e de diferentes escalas incorporam diferentes identidades espaciais. Nossa experiência delas parece intrínseca àquilo que as cidades são. (Hillier, 1989, p. 5, apud Holanda, 2002, p. 89)

Hillier analisou comparativamente cidades de diferentes culturas e escalas. Mas a análise também tem sido feita na escala intraurbana, uma vez que a área urbana pode ser caracterizada como formada por populações com diferentes culturas, etnias, estratos de renda etc., e essas populações têm expectativas diversas ante o espaço, e tendem a modificá-lo de acordo com seu perfil, assim como se agregam, em muitos casos, na forma de quase-guetos.

Para Peponis (1989), tratar da arquitetura da cidade implica considerá-la mais globalmente que localmente, pois a arquitetura pode exercer efeitos mais abrangentes do que locais:

A experiência de ambientes genuinamente urbanos refere-se ao encontro, embora não necessariamente à interação, entre pessoas, na maioria das vezes desconhecidas, que podem ser identificadas como pertencentes a diferentes classes sociais, status, raça ou origem étnica: refere-se também à exploração do que não é costumeiro, e ao conhecimento de outros modos de vida, ainda que deles não participemos. (Peponis, 1989, p. 1)

Por isso, o espaço urbano pode ser visto como meio de circulação de pessoas e idéias, mais do que interação entre elas. A interação é uma possibilidade colocada à disposição dos habitantes por uma configuração urbana que a favorece - mesmo quando a possibilidade não é usada, ela é um recurso cultural importante. 
O processo de produção e a estrutura resultante do espaço urbano refletem a cultura que o produz e organiza. Entretanto, este é apenas um olhar possível: uma vez pronto, o espaço urbano transforma-se, mais ou menos, em algo inteligível e apropriável, segundo os interesses e as possibilidades de cada indivíduo ou grupo de indivíduos. Essa inteligibilidade acontece de forma mais global (as grandes superfícies urbanas) que local (a rua, a praça). A escala global tem importância social crucial, normalmente negligenciada pela literatura arquitetônica, mais preocupada com a edificação isolada, quando muito a rua ou a praça. Talvez essa seja a inovação mais importante da sintaxe espacial (Peponis, 1989).

É essa organização global a responsável pelo uso intenso de determinados trechos urbanos que atrai o interesse das pessoas, seja para fins residenciais ou comerciais, ao mesmo tempo em que, não intencionalmente, elas são vigiadas. A existência de grande circulação traz um sentimento de segurança sem esforços especiais (Peponis, 1989).

Assim, o espaço urbano também se define pelo modo como as pessoas se apropriam e circulam nele, o que o revela como mais ou menos acessível, de acordo com o contexto sócio-histórico analisado. Esse tipo de análise permite identificar padrões artificiais mais sistemáticos "que as pessoas parecem manter e tornar significativo quando elas circulam na cidade" (Peponis, 1989, p. 17). Neste trabalho, a acessibilidade global do espaço, indicada pela medida de integração, é considerada um recurso cultural precioso, isto é, as características e necessidades da população que usufrui determinado espaço é que determinam as formas de circulação nele, e não o projeto em si.

\section{Ociosidade per capita da infra-estrutura}

Calculou-se também duas medidas globais de acessibilidade à infraestrutura. A primeira refere-se o índice médio de utilização da infraestrutura pela população, tendo como referência os eixos viários. É a razão entre população total e comprimento total dos eixos viários. A segunda, de certa maneira, inverte a primeira: é um “índice de ociosidade”.

Do comprimento total das vias urbanas subtrai-se o comprimento total das vias utilizadas; obtêm-se o comprimento total de vias ociosas, aquelas que passam por áreas não ocupadas (partes da cidade onde não há setores censitários do Censo do IBGE); divide-se o comprimento total dessas vias ociosas pela população total. $\mathrm{O}$ resultado indica quantos metros per capita de infraestrutura viária encontra-se "ociosa” (o termo vai por conta da subutilização, porque sua única função é conectar áreas separadas por vazios urbanos, sem alimentar nenhuma atividade ao longo dessas áreas) (Ribeiro, 2008).

\section{As variáveis - método}

\section{Índice de Dispersão}

O cálculo de Bertaud e Malpezzi (2003) para o Índice de Dispersão é interessante, pois ilustra como a cidade ocupa o espaço, permite fazer considerações a respeito de 
custos de deslocamento, implementação de infraestrutura, urbanização. Todavia, sem saber de antemão qual o intervalo de variação possível, é difícil fazer análises comparativas e ter leitura mais fácil da posição de uma determinada cidade quanto à dispersão, no âmbito da amostra.

Assim, utilizou-se uma transformação linear que transpõe os números absolutos em relativos, representada pela Equação 1.

$$
y=\frac{a(x+1)}{2}+b \Rightarrow x=\frac{2(y+b)}{a}+1
$$

Para atualizar os dados referentes ao Brasil, utilizou-se o Censo de 2000 (IBGE, 2002) (os cálculos efetuados por Bertaud e Malpezzi [2003] foram feitos com dados de 1991). Além de atualizar os dados para cidades brasileiras calculadas por eles (Distrito Federal, Rio de Janeiro e Curitiba), foram incluídos dados de mais 10 capitais: Belém, Belo Horizonte, Recife, Porto Alegre, Florianópolis, Salvador, Natal, Fortaleza, João Pessoa e São Paulo, totalizando 60 centros urbanos.

O cálculo do índice de dispersão efetuado para as 13 cidades brasileiras foi feito a partir da Equação 2, adaptada por Holanda (2003), apenas para maior clareza (ela não muda os resultados), a partir da equação proposta por Bertaud e Malpezzi (1999; 2003):

$$
\rho=\frac{\sum_{i} d_{i} p_{i}}{P C}
$$

onde $\rho$ é o índice de dispersão, $d$ é a distância do centróide de cada setor urbano ao CCS, $p$ é a população de cada setor urbano, $P$ é a população urbana total, e $C$ é a média dos pontos de um círculo de área equivalente à da cidade analisada ao seu centro (que é igual a 2/3 do raio desse círculo, valor obtido por meio de cálculo integral). (Holanda, 2003:50)

Após a atualização e cálculo do Índice de Dispersão para as 13 cidades brasileiras, normalizou-se os dados das 60 cidades, a partir da Equação 1. Assim, obteve-se o Índice de Dispersão Normalizado.

Esse índice tem um único valor por cidade, pois é sistêmico, definido para o conjunto urbano, ao contrário dos demais que, como veremos, podem caracterizar as partes distintas do sistema. 


\section{Índice de Integração}

Por meio de procedimentos computacionais, com o software Depthmap 6.824r, foi calculado o Índice de Integração para cada eixo viário, o que, numericamente, indica sua relativa acessibilidade em relação a todo o sistema. Essa acessibilidade, entretanto, é mais de ordem topológica do que geométrica, na medida em que se refere ao mínimo de linhas intervenientes entre cada linha e todas em relação a todo o sistema. Em outras palavras, o índice de integração revela como é fácil se deslocar a partir de cada linha para qualquer outra do sistema.

Para calcular o Índice de Integração Normalizado por setor censitário foram consideradas todas as linhas que passam pelo setor, e a integração do setor é identificada como sendo a mesma da linha mais integrada dentro dele.

O processo de cálculo do Índice de Integração Normalizado iniciou-se pela normalização do Índice de Integração Máxima, baseada em uma escala de -1 a +1 . Foi calculado o ponto médio da distribuição das duas variáveis, essa medida de tendência central separa o conjunto de valores em duas partes iguais, de forma que o valor encontrado é considerado como ponto de corte entre alta e baixa integração.

\section{Densidade Viária}

Outra medida utilizada neste trabalho é a medida de número de habitantes por setor censitário divido pelo comprimento do metro linear das vias que se encontram circunscritas ao setor censitário. Essa medida indica o grau de acesso da população à infraestrutura urbana. Esse resultado foi normalizado, por meio da Equação 1, em uma escala de $-1 \mathrm{a}+1$, a qual indica que quanto menores os valores da escala menos acesso a infraestrutura e quanto maior os valores mais intensamente ela é utilizada pela população (Ribeiro, 2008).

\section{Ociosidade per capita}

Essa medida é interessante quando comparada com a de outras cidades, da mesma forma como é feito por Bertaud e Malpezzi para o Índice de Dispersão. Ademais, informa melhor sobre a dispersão territorial de cidades como Florianópolis, cuja compacidade medida pelo método de Bertaud e Malpezzi é alta porque há grande concentração demográfica próxima ao CCS. Contudo, isso mascara o fato de a cidade ser muito espraiada, com uma infraestrutura muito ociosa, por cobrir áreas de muito baixa densidade ou desocupadas, o que impacta fortemente em custos urbanos. Para este trabalho utilizou-se a comparação com três grandes metrópoles do país, Rio de Janeiro, São Paulo e Florianópolis. A partir da diferença dessas medidas pode-se avaliar o nível de ociosidade existente, isto é, locais por onde há infraestrutura e não há ninguém para utilizá-la. Assim, passa-se a ter uma medida que pode revelar questões relacionadas ao custo da infraestrutura, nível de oferta e de demanda (Ribeiro, 2008). 


\section{Resultados e discussões}

\section{Índice de Dispersão}

Verificou-se, a partir do cálculo desse índice para 60 cidades no mundo, que não há um agrupamento significativo das cidades de um único país ou região geográfica. A partir da coluna de regióes pode-se notar que as cidades mais compactas (entre 0,5 e 1,0) são encontradas na América do Norte, Ásia, e Europa. Nos países da América Latina e Caribe e África há maior ocorrência de cidades dispersas (0,5 a -1,0) (Quadro 1). Essa distribuição é reflexo do processo histórico-cultural de formação dessas cidades em suas respectivas regiões no mundo. Em relação ao Brasil, das treze cidades analisadas apenas duas apresentaram valores negativos (mais dispersas). Isso se deu provavelmente em função do processo histórico e social de formação dessas cidades, bem como por sua evolução, devido a características intrínsecas de cada região. Além disso, os limites utilizados afetaram o resultado.

QUADRO 1| Percentual de cidades por região em função do Índice de Dispersão Normalizado (IDN)

\begin{tabular}{|c|c|c|c|c|}
\hline $\begin{array}{l}\text { IDN } \\
\text { REGIỐES }\end{array}$ & $-1,0$ a $-0,5$ & $-0,5$ a 0,0 & 0,0 a 0,5 & 0,5 a 1,0 \\
\hline AMÉRICA LATINA E CARIBE & $7,14 \%$ & $7,14 \%$ & $64,29 \%$ & $21,43 \%$ \\
\hline AMÉRICA DO NORTE & $0,00 \%$ & $0,00 \%$ & $18,18 \%$ & $81,82 \%$ \\
\hline EUROPA & $0,00 \%$ & $0,00 \%$ & $6,25 \%$ & $93,75 \%$ \\
\hline PAÍSES ÁRABES & $0,00 \%$ & $0,00 \%$ & $50,00 \%$ & $50,00 \%$ \\
\hline ÁFRICA & $0,00 \%$ & $33,33 \%$ & $66,67 \%$ & $0,00 \%$ \\
\hline ÁSIA E PACÍFICO & $7,14 \%$ & $7,14 \%$ & $7,14 \%$ & $78,57 \%$ \\
\hline
\end{tabular}

FONTE ELABORAÇÃO PRÓPRIA.

A atualização dos dados de Brasília, Rio de Janeiro e Curitiba, que utilizou os setores censitários do Censo de 2000 (IBGE, 2002), mostrou uma discrepância nos valores encontrados por Bertaud e Malpezzi (2003), com redução desses valores, principalmente para Brasília. O resultado obtido por aqueles autores mostra a Capital como a cidade mais dispersa dentre as analisadas. Com a utilização de dados mais precisos (setores censitários), Brasília apresentou-se como a segunda cidade mais dispersa, reduzindo o valor de 3,26 (primeiro cálculo efetuado por Bertaud e Malpezzi em 2003) para 2,62 (segundo cálculo, realizado neste trabalho), uma redução de 19,63\%. 
O resultado da normalização mostrou que há uma tendência de ocorrência de cidades compactas. Das cidades analisadas, 3,33\% encontram-se entre -1,00 e - 0,50 , que indica forte tendência para uma forma dispersa; $5,00 \%$ das cidades encontram-se entre $-0,50$ e 0,00 , que mostra uma tendência entre uma forma dispersa a uma forma intermediária; 26,67\% encontram-se entre 0,00 e 0,50, que indica uma tendência entre uma forma intermediária a uma forma compacta; e 65,00\% encontram-se entre 0,50 a 1,00, que mostra que boa parte das cidades tende para uma forma fortemente compacta.

Esse resultado mostrou que a maioria das cidades tem tendência a uma forma mais compacta, e uma pequena parte (apenas cinco cidades, Hong Kong, Capetown, Brasília, Belo Horizonte e Bombay) apresentou uma tendência à forte dispersão espacial.

O Gráfico 1 mostra a relação entre o Índice de Dispersão Normalizado e a população urbana de cada cidade. Pode-se verificar a tendência da maioria das cidades analisadas para compacidade. Esse gráfico mostra que o grau de compacidade não tem correlação direta com o tamanho da população, uma vez que a distribuição mostra-se aleatória, com um coeficiente de correlação de Pearson (r) igual a 0,007 e o seu respectivo coeficiente de determinação $\left(\mathrm{r}^{2}\right)$ é 0,00005 , o que indica que essas variáveis não se influenciam. Outros fatores podem estar relacionados à dispersão, tais como fatores culturais, históricos, ambientais, etc. Esse gráfico nos permite especular que a dispersão é causada pela forma como a população se apropria do espaço, que depende mais de fatores como o custo da terra e a oferta de empregos, do que propriamente o número de habitantes.

GRÁfICO 1 | Relação entre o Índice de Dispersão Normalizado e a população em área urbana

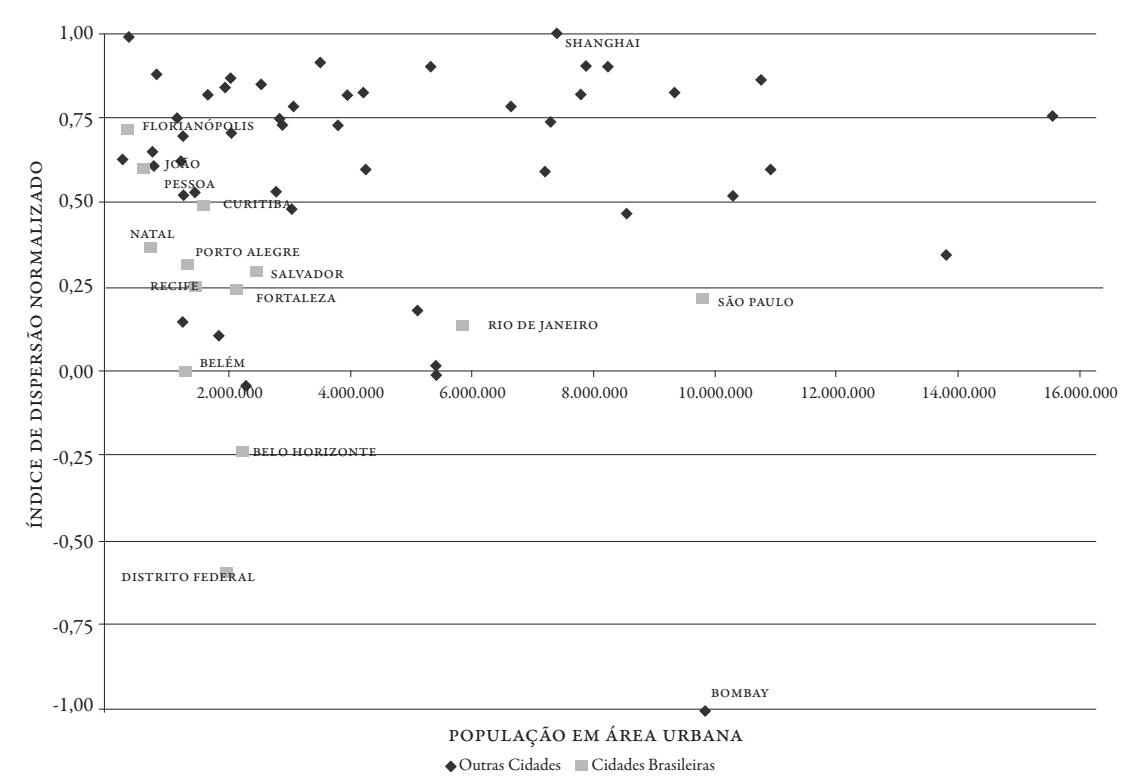

FONTE ELABORAÇÃO PRÓPRIA. 
Têm-se cidades com número de habitantes muito próximos, mas com índices de dispersão muito diferentes como, por exemplo, a cidade de Shanghai, na China, que apresenta índice de dispersão normalizado igual a 1,0, e pode ser considerada a mais compacta dentre as cidades analisadas, com uma população de aproximadamente 11.000.000 de pessoas (Bertaud \& Malpezzi, 2003). Por outro lado, tem-se a cidade de Bombay, na Índia, com índice de dispersão normalizado igual a -1,0, e pode ser considerada a mais dispersas dentre as cidades analisadas, com uma população de aproximadamente 10.000.000 de pessoas (Bertaud \& Malpezzi, 2003).

O Gráfico 2 mostra a relação entre o Índice Dispersão Normalizado e a área urbana construída. Verifica-se, da mesma forma como ocorre no Gráfico 1, que não é possível identificar tendências ou agrupamentos, apesar de ter apresentado uma fraca correlação positiva, esta é muito baixa para expressar de fato alguma relação entre estas variáveis $(\mathrm{r}=0,131)$. O coeficiente de determinação também se mostra muito pequeno $\left(r^{2}=0,017\right)$, o que indica, como anteriormente, que essas variáveis não se influenciam. A maioria das cidades apresenta alta compacidade, não importando o tamanho de sua área urbana. Novamente somos inclinados a acreditar que a forma como a população se apropria do espaço é preponderante para influenciar a dispersão. No Distrito Federal, o custo da terra próximo ao centro, concentrador de empregos e serviços, é extremamente alto (entre U\$5.000 a U\$8.000 por metro quadrado). Esse fato faz com que a população busque ocupar áreas com menor custo, que consequentemente se localizam afastadas do centro. Essa situação gera uma alta demanda de transporte, acarretando aumento nos preços das tarifas (pois não há sub-centros atrativos entre as áreas urbanas e o centro do DF), além de gerar um alto custo para o governo que tem que investir em longos trechos de ligação.

$\mathrm{O}$ aumento do custo de transporte pode ser verificado pelo Índice de Passageiros por Quilômetro (IPK) que, em linhas gerais, indica a média de passageiros transportados por quilômetro de linha de ônibus. Quanto menor o IPK mais caro se torna o transporte, o que pode indicar distâncias longas a serem percorridas com baixa quantidade de passageiros. No caso de Brasília, cidade com menor IPK entre as cidades brasileiras estudadas, comumente não há troca de passageiros durante o percurso. A maioria entra nos pontos iniciais e desloca-se até o ponto final, a rodoviária do Plano Piloto. Segundo dados da Pesquisa Domiciliar de Transporte de 2000, cerca de 44,92\% dos empregos formais do Distrito Federal encontram-se no Plano Piloto, sendo que menos de $10 \%$ da população do DF habita nesta localidade (Codeplan, 2003).

A maioria das cidades brasileiras encontra-se numa faixa intermediária da normalização, mas com tendência para maior compacidade. Três cidades apresentaram valores iguais ou menores que 0,00 : Belém $(0,00)$, Belo Horizonte $(-0,24)$ e Distrito Federal $(-0,60)$. As 13 capitais brasileiras analisadas apresentam comportamento heterogêneo, o que impossibilita seu agrupamento. Esse fato deve-se, provavelmente, à época de sua fundação, história de formação, evolução de cada uma delas, aspectos ambientais e físicos do local de instalação dessas cidades, enfim, esse fato possivelmente deve-se à situação de formação específica de cada centro, sendo uns com quase 500 anos, outros com menos de 80 anos. 
GRÁfico 2 | Relação entre o Índice de Dispersão Normalizado e a área urbana construída

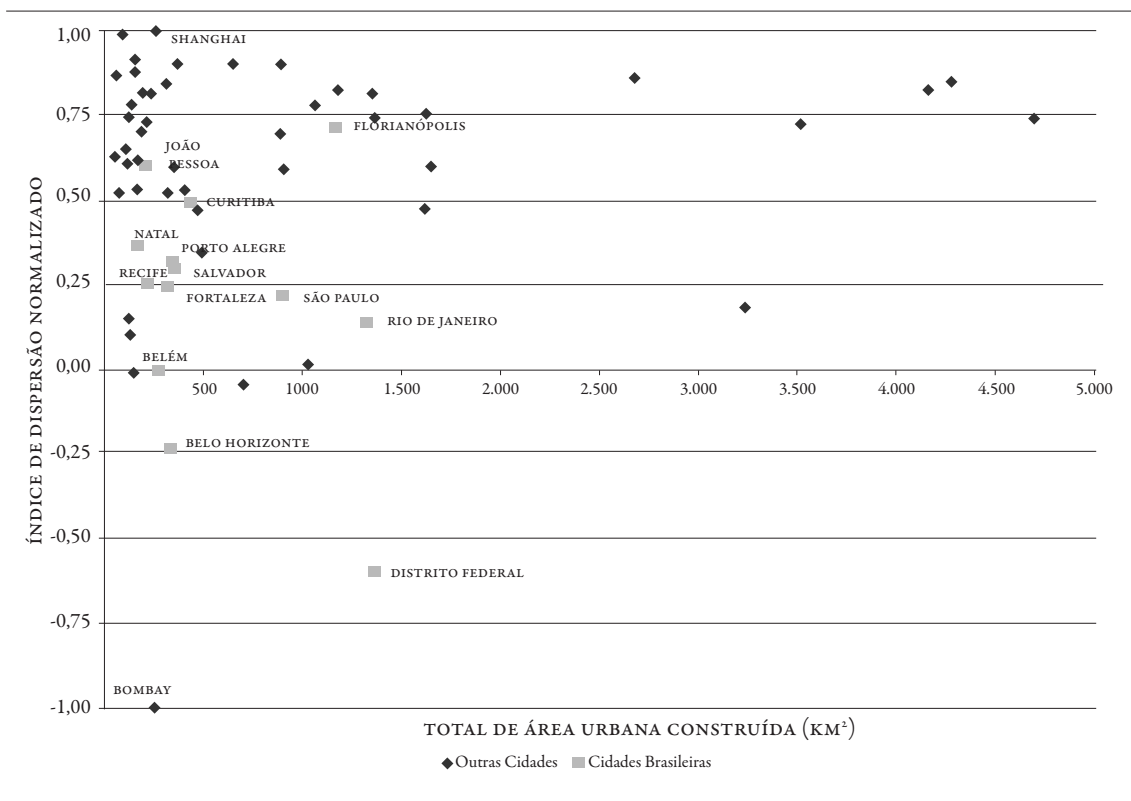

FONTE ELABORAÇÃO PRÓPRIA.

Na maioria das cidades prevalece a redução da população em função da distância ao CCS, comportamento semelhante ao encontrado para a maioria dos centros mundiais analisados por Bertaud e Malpezzi (2003). Apenas Brasília, Moscou e Johanesburgo apresentam comportamento inverso. Isso possivelmente ocorre devido ao forte controle do Estado, que dita regras rígidas de controle de ocupação. Apenas Brasília apresenta comportamento inverso, a população aumenta à medida que a distância do CCS aumenta. Isto se deve às políticas públicas perversas, que em nome da preservação do projeto do Plano Piloto, acabam por fomentar a ocupação de espaços vazios periféricos, o que favorece uma ocupação fragmentada do espaço e causa uma rede urbana desconexa. Como resultado, gera-se forte segregação espacial e exclusão social: as áreas com famílias de menor poder aquisitivo localizam-se distantes do Plano Piloto, pois quanto mais próximo dele, mais caro é o custo de vida. Este comportamento inverso propicia maior número de pessoas distantes do CCS, consequentemente, longe do mercado principal de empregos, o que implica alto custo de transporte na cidade. Como o centro é o grande concentrador de empregos, o valor da terra se torna cada vez mais alto, pois a demanda por habitar próximo ao local de trabalho também aumenta. Gera-se assim um círculo vicioso entre o preço da terra, demanda habitacional e oferta de empregos.

\section{Índice de Integração}

A Figura 1 mostra a disposição dos eixos axiais para todo o DF, na qual foram destacadas as vias mais acessíveis ( $2 \%$ do sistema viário). Pode-se notar que a via mais 
integrada vai desde o Setor de Postos e Motéis até a cidade de Sobradinho. Isso se deve ao fato de que esse conjunto compõe praticamente uma única via, ligando pontos distantes da cidade. Outra via com alta integração é o Eixo Rodoviário Norte, que se conecta com o conjunto viário citado. Existem outras vias com alta acessibilidade, mas o conjunto citado destaca-se devido à sua grande extensão e conexões.

FIGURA 1 | Eixos axiais com seu respectivo índice de integração

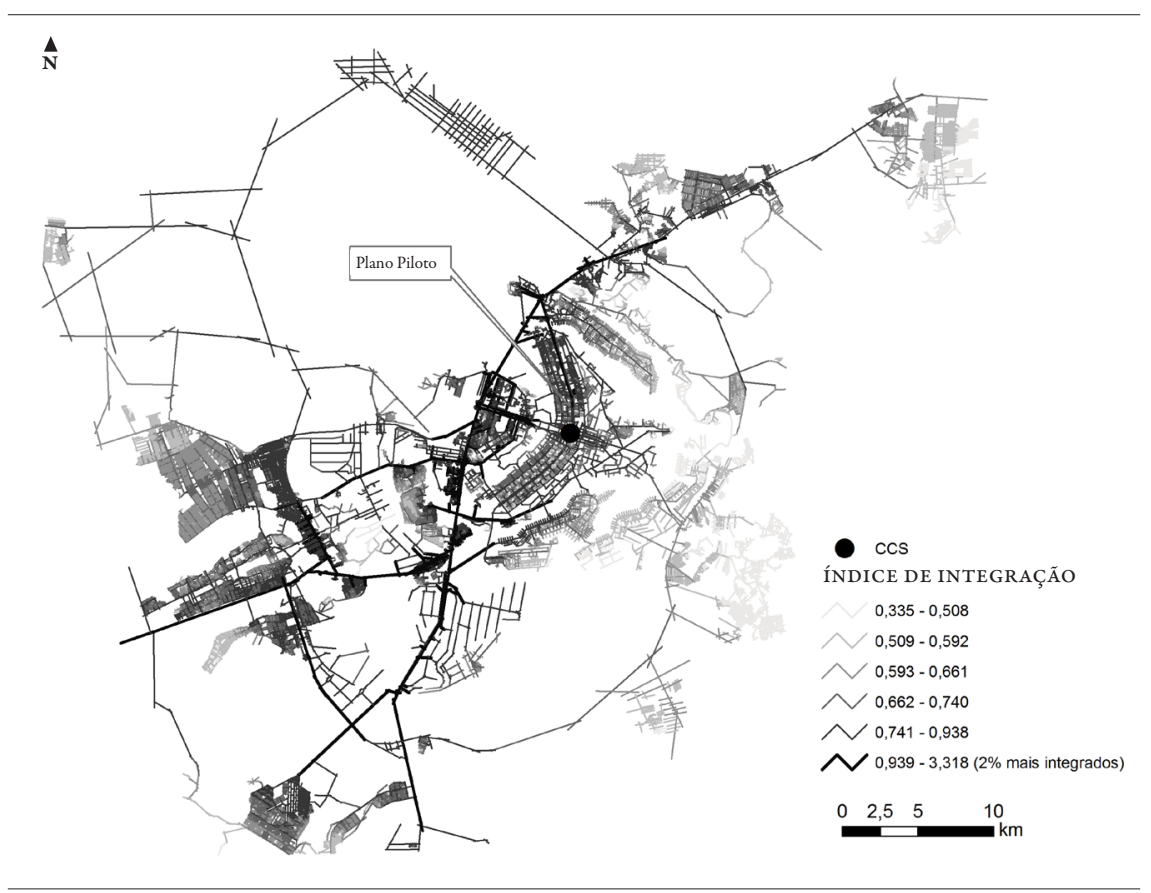

FONTE ELABORAÇÃO PRÓPRIA.

A Figura 2 mostra o resultado da transposição dos valores dos eixos axiais para os setores censitários. É interessante notar que o Plano Piloto não é a área mais acessível do sistema viário da capital, e que essa se localiza em seu entorno imediato. Nota-se que as áreas mais integradas não se localizam tão próximas ao CCS. Isto se deve à estruturação da cidade, com um peso relativamente maior do número de vias localizadas a oeste. O eixo de maior integração liga regiões distantes do DF, passa pela Rodoferroviária, local de chegada e partida de ônibus interestaduais, passa pelo Setor de Abastecimento e Armazenagem Norte (SAAN), e dá acesso à região Nordeste e Sudeste do país.

A correlação entre a integração máxima por setor censitário e a distância ao CCS apresentou um resultado de -0,429. Esse resultado indica que há uma relação inversa entre as variáveis, isto é, quanto menor a distância ao CCS maior a integração viária. Apesar do valor de correlação não ser alto, segundo Levin e Fox (2004), ela expressa tanto a direção quanto a intensidade (uma correlação negativa de moderada a forte). 


\section{FIGURA 2 | Integração máxima por setor censitário}

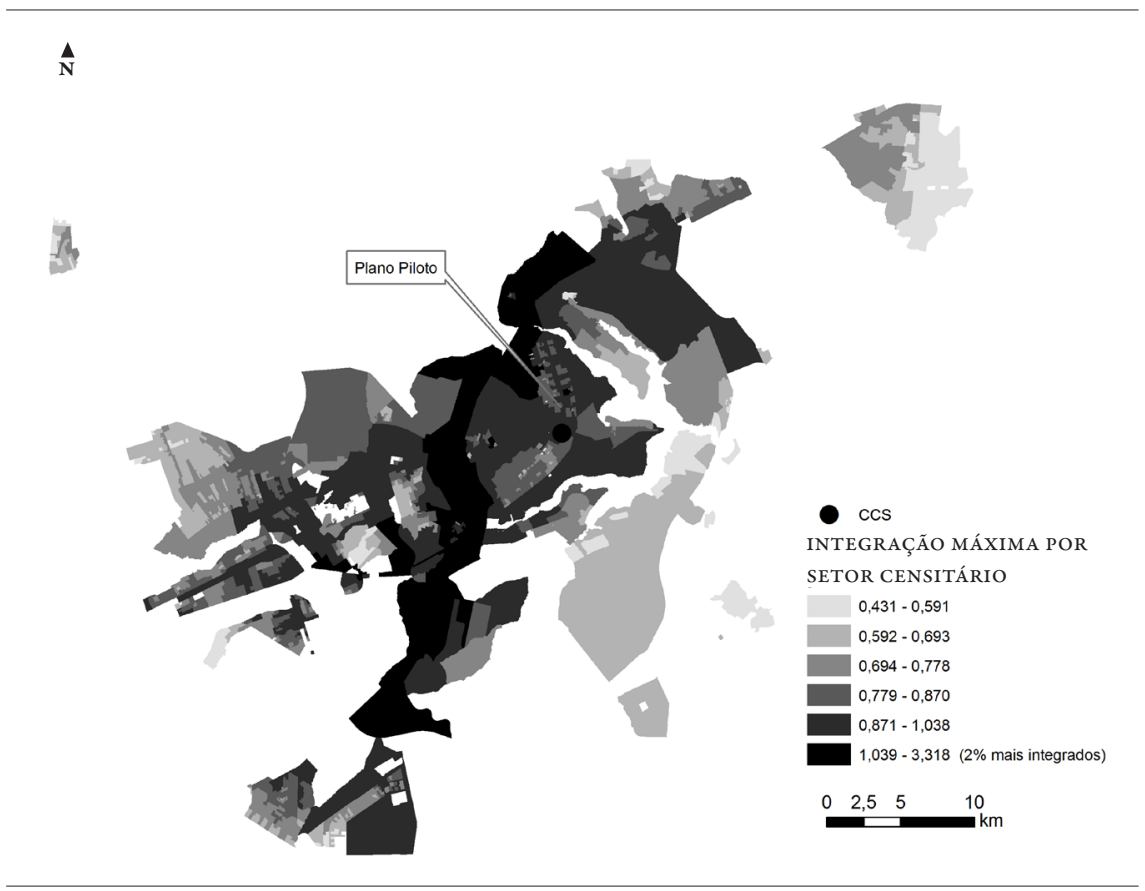

FONTE ELABORAÇÃO PRÓPRIA.

Esse resultado reforça o que já se sabe na prática, as cidades mais afastadas do centro apresentam menor integração ao sistema de circulação. A perversidade do planejamento faz-se presente na estruturação da capital federal; quem tem melhores condições financeiras ou cargos importantes habita as áreas mais próximas, quem não tem dinheiro para custear a vida no centro, tem que procurar habitação em locais cada vez mais afastados, barateando o custo de moradia, mas aumentando o custo com transporte.

Pode até parecer contraditório, mas Brasília (referência à área tombada) sofre com a questão do embelezamento do centro, processo no qual o centro é mantido agradável e belo e a pobreza e "feiúra" são mantidas o mais afastadas possível. O que se verifica é o Plano Piloto mantido a qualquer custo, e em sua volta o crescimento com pouco ou com nenhum controle, devido à demanda habitacional crescente na capital do país. Brasília é estruturada com base na circulação de veículos, com isto as pessoas não são estimuladas a apreciar a própria cidade. $O$ pedestre é quase sempre desconsiderado e a possibilidade de interações sociais torna-se extremamente reduzida. A lógica dessa cidade pode ser considerada perversa, os veículos estão nos espaços públicos e as pessoas nos espaços privados.

A Figura 3 ilustra a integração máxima normalizada por setor censitário. Pode-se observar que a normalização ressalta as situações de maior e menor integração, bem como de maior ou menor distância do CCS. 
FIGURA 3 | Integração máxima normalizada

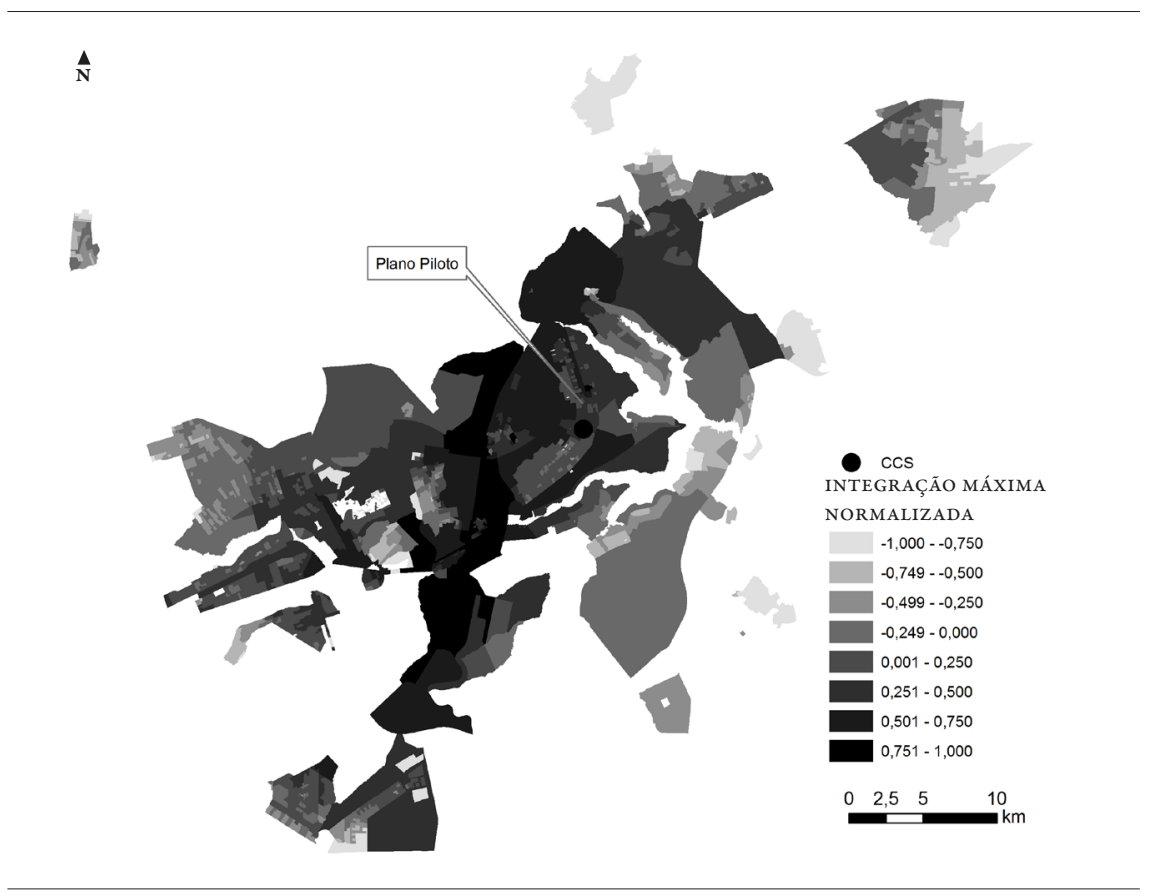

FONTE ELABORAÇÃO PRÓPRIA.

Com o aumento populacional e a atual configuração da cidade baseada na circulação de veículos, a população de renda mais baixa, a maioria originada por migrantes rurais, passa a ocupar as áreas mais periféricas da cidade, apropria-se desse espaço e molda-o conforme seus próprios critérios. Para Romero (2001, p. 91), "o lugar evoca o sentido de filiação a um grupo social”, isto faz com que as pessoas atribuam valores a esse espaço que remontem à sua origem.

Em função disso, é comum nas cidades brasileiras que as áreas ocupadas por população de baixa renda encontrem-se desprovidas de áreas verdes (como praças, parques, árvores, arbustos, entre outros), organização e infraestrutura de qualidade. Normalmente, são áreas com ruas tortuosas (que não são necessariamente um mal à configuração local, cada caso deve ser analisado individualmente) e estreitas, casas geminadas e com pouco ou nenhum espaço para lazer. Em várias áreas periféricas brasileiras, as condições ambientais, tais como circulação de vento, sombreamento natural, verde urbano, são muito prejudicados, e em situações extremas, inexistentes, o que gera verdadeiros hot spots urbanos.

\section{Densidade viária}

Para mensurar a acessibilidade da população à infraestrutura calculou-se a relação de habitantes por metro linear de vias, que foi chamada de densidade viária. Uma vez que, como explicado, o sistema de infraestrutura normalmente acompanha o sistema viário, assim, pode-se usar este para deduzir aquele. 
Nas cidades periféricas também foram encontrados altos valores para essa medida, como era esperado, uma vez que a densidade de ocupação é maior que nas áreas próximas ao CCS. Nas áreas consideradas de alto padrão (Lago Sul, Lago Norte e Park Way) os valores são baixos, devido à baixa ocupação populacional em função dos grandes lotes que compõem essas áreas (acima de $800 \mathrm{~m}^{2}$ ).

A Figura 4 mostra a densidade viária normalizada. É interessante notar que as áreas que apresentam maiores valores estão relacionadas às áreas urbanas consolidadas e densamente ocupadas. As áreas com menores valores estão relacionadas às cidades de maior poder aquisitivo, essas constituídas por grandes lotes urbanos e por áreas formadas por eixos de ligação, nas quais há infraestrutura, porém um número muito pequeno ou inexistente de habitantes. Isto indica áreas urbanas com infraestrutura subutilizada (existe boa infraestrutura mas poucas pessoas a usufruem). Resulta que os custos de implantação e manutenção da infraestrutura são mais elevados e que, se a população pagasse por essas diferenças, isso pesaria negativamente na qualidade de vida dessas áreas, pelo ônus adicional que isso implicaria. Sabe-se, lamentavelmente, que isso não funciona assim, pois os mais pobres subvencionam os mais ricos (não há uma política equitativa de cobrança dos custos infraestruturais, muito menos uma política redistributiva). Contudo, o fato não elimina a importância da caracterização aqui realizada, nem o potencial de sua utilização, a depender da vontade política para tal.

FIGURA 4 | Ilustração da medida de densidade viária normalizada

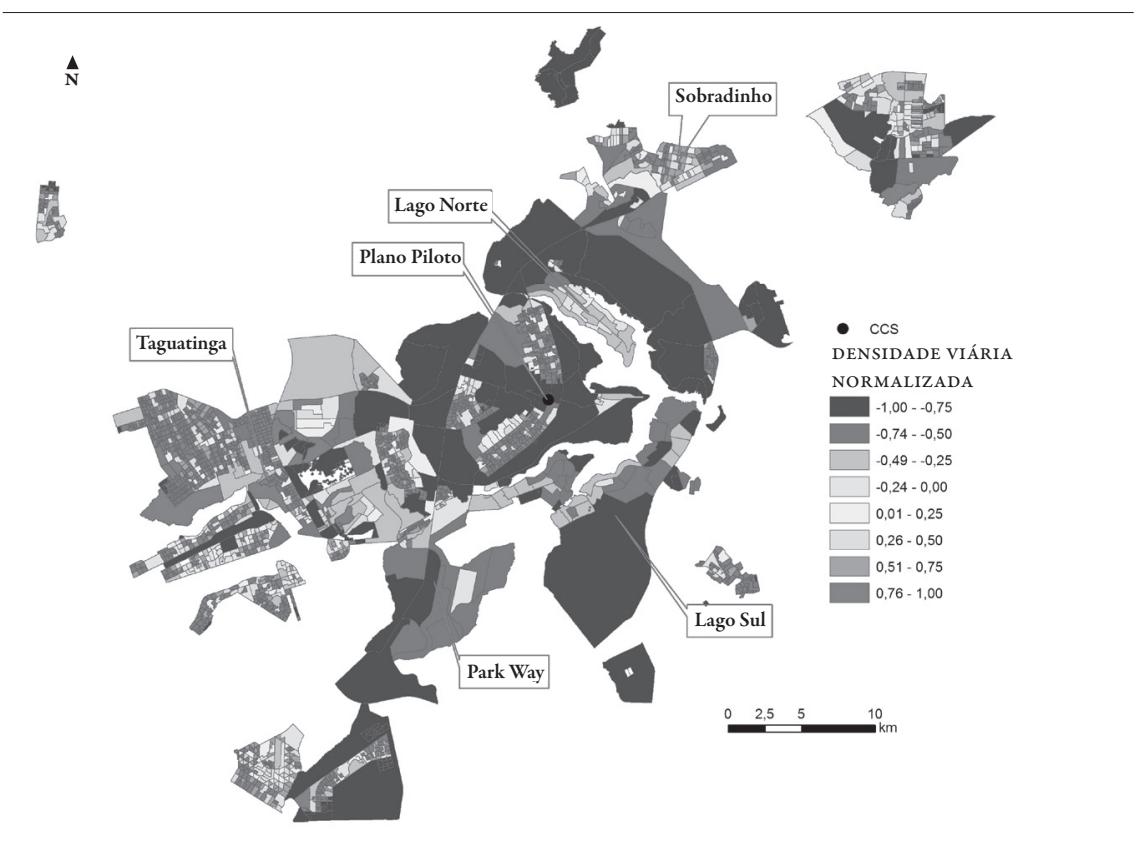

FONTE ELABORAÇÃO PRÓPRIA. 
Conforme pode ser visto no Quadro 2, o cálculo da medida global de acessibilidade à infraestrutura mostra que, ao considerarem-se todos os eixos do sistema, o Distrito Federal apresenta o segundo resultado mais baixo de densidade viária, sendo o pior resultado encontrado para Florianópolis. Ao avaliarem-se somente as vias que estão circunscritas aos setores censitários urbanos, isto é, apenas as vias que passam em áreas consideradas como urbanas pelo IBGE, a relação se mantém. Isso reflete a baixa utilização de infraestrutura urbana para as duas capitais. Florianópolis apresenta uma situação pior que a do Distrito Federal em função da forte ocupação próxima ao seu CCS, e uma estrutura urbana dispersa composta por longos eixos de ligação entre o CCS e as demais zonas urbanas. Para o Distrito Federal a situação é semelhante, a diferença entre as duas capitais resulta de que as cidades periféricas no Distrito Federal são densamente ocupadas, o que gera uma demanda maior na rede de infraestrutura, enquanto Florianópolis apresenta somente alta densidade próxima ao centro e baixa ocupação em sua periferia.

São Paulo e Rio de Janeiro apresentaram melhores resultados, principalmente o Rio de Janeiro que chegou a quase um habitante por metro linear de via. Essas duas capitais apresentam alta densidade em sua área urbana, o que implica grande otimização da rede de infraestrutura.

QUADRO 2 | Medidas globais de densidade viária e de ociosidade de vias per capita

\begin{tabular}{l|ccc}
\hline CAPITAIS & HAB/VIAS TOTAIS & HAB/VIAS URBANAS & $\begin{array}{c}\text { OCIOSIDADE PER } \\
\text { CAPITA }^{*}\end{array}$ \\
\hline DISTRITO FEDERAL & 0,31 & 0,36 & 0,47 \\
SÃO PAULO & 0,52 & 0,55 & 0,12 \\
RIO DE JANEIRO & 0,81 & 0,86 & 0,07 \\
FLORIANÓPOLIS & 0,13 & 0,15 & 0,6 \\
\hline
\end{tabular}

(*) Metros Lineares PER CAPITA DE INFRAESTRUTURA VIÁRIA QUE NÃo SERVEM DiRETAMENTE A NENHUMA ATIVIDADE.

FONTE ELABORAÇÃo PRÓPRIA.

\section{Ociosidade per capita}

A ociosidade per capita mostra, de forma inversa à anterior, a relação de vias que não passam em áreas consideradas urbanas pelo IBGE em função da população, e assim a quantidade de metro linear de infraestrutura que não é diretamente aproveitada pela população. Da mesma maneira que as medidas anteriores, essa medida apresenta os piores resultados para o Distrito Federal e Florianópolis, como era esperado.

A dispersão urbana das duas cidades gera uma ociosidade maior da rede de infraestrutura, uma vez que é necessária a construção e manutenção de longos tramos de redes, sem ligações domiciliares ou outras, para atender aos aglomerados mais distantes. Esse é um índice global para a cidade, não um índice adstrito a cada setor censitário individualmente. Como tal, funciona como o índice de dispersão de Ber- 
taud e Malpezzi, mas o complementa de maneira importante, pois capta aspectos da dispersão urbana não identificados por eles. É, portanto, utilizado na composição do índice final de forma a melhorar a medida de dispersão de Bertaud e Malpezzi (1999), modificada neste trabalho, a fim de representar também a dispersão da infraestrutura (que tem custos óbvios), não somente a dispersão demográfica (que é o forte do índice de Bertaud e Malpezzi). É muito interessante, por exemplo, verificar como Florianópolis tem ótimo desempenho no índice de Bertaud e Malpezzi e péssimo neste aqui proposto.

Os dados de ociosidade viária foram normalizados a partir da Equação $1 \mathrm{em}$ uma escala de -1 a +1 (Quadro 3). Quanto mais próximo de -1, maior é a ociosidade da rede e quanto mais próximo de +1 , menor é a ociosidade.

QUADRO 3 | Medidas globais de densidade viária e de ociosidade de vias per capita

\begin{tabular}{l|c|c}
\hline \multicolumn{2}{l}{ CIDADES } & \multicolumn{2}{l}{$\begin{array}{l}\text { OCIOSIDADE PER CAPITA } \\
\text { NORMALIZADA }\end{array}$} \\
\hline DISTRITO FEDERAL & 0,47 & $-0,51$ \\
SÃO PAULO & 0,12 & 0,81 \\
RIO DE JANEIRO & 0,07 & 1,00 \\
FLORIANÓPOLIS & 0,60 & $-1,00$ \\
\hline
\end{tabular}

FONTE ELABORAÇÃO PRÓPRIA.

Outro fator associado à dispersão da população é o aumento da circulação de veículos, que além de elevar a quantidade de poluentes no ar, também eleva a temperatura, em função da emissão de gases aquecidos pelos veículos. Nas áreas de maior circulação de pessoas e veículos e concentradoras de empregos, como o Setor Comercial Sul e o Centro de Taguatinga, verificam-se metais no ar muito acima do que permite a legislação (Bitencourt, 2004; Damaso, 2004) e altos valores de temperatura, se comparados a regiões próximas a seus entornos.

\section{Considerações finais}

No período de 2001 a 2008, a população em idade ativa (PIA) do Distrito Federal teve um aumento $24,2 \%$. É em maioria feminina e a proporção em relação ao sexo foi estável. Houve um aumento de 3,5 pontos percentuais na população em idade ativa não branca. A faixa etária com maior participação na PIA é a que tem entre 25 e $39 \operatorname{anos}(32,1 \%)$, seguida pela faixa que tem entre 40 e 59 anos $(26,8 \%)$. Houve um aumento na PIA com mais de 12 anos de estudo de 7,5 pontos percentuais. Além disso, também aumentou, em menor proporção, a PIA na faixa de nove a onze anos de estudo (4,1 pontos percentuais). A maior concentração da PIA está na faixa de renda entre um e três salários mínimos. 
A partir das análises feitas, verifica-se que há menor inserção de mulheres no mercado de trabalho, isto significa que há mais mulheres desempregadas. $\mathrm{O}$ desemprego também é maior entre os não brancos. Em relação à idade, o desemprego é maior nas faixas de 15 a 24 anos (24,7\%) e entre 25 e 39 anos (10,4\%). Quando se analisa em relação ao tempo de estudo, observa-se que a maior taxa desemprego está na população entre nove e onze anos de estudo (14,2\%). Também vale ressaltar que o único grupo que teve queda na taxa de ocupação (o que significa maior taxa de desemprego) foi o da população com mais de 12 anos de estudo, apesar de ter sido o grupo no qual a PIA mais cresceu (7,5 pontos percentuais).

A estrutura sócio-ocupacional não sofreu muita alteração no período de 2001 a 2008. A predominância das ocupações médias se manteve (34\%), seguida dos trabalhadores do terciário (19\%) e do terciário não especializado (17,7\%). A participação de dirigentes é de apenas 1,5\% e dos profissionais de nível superior é de 12,1\%.

Quando se analisa o comportamento das categorias sócio-ocupacionais (CATs) quanto à divisão por sexo, verifica-se que a participação masculina é consideravelmente maior nas categorias de trabalhadores do secundário $(90,6 \%)$, de dirigentes $(73,7 \%)$ e de pequenos empregadores (62,9\%). Nas CATs em que há predominância de mulheres, a diferença não é tão grande quanto as que têm maioria masculina.

De forma geral, a utilização dos índices configuracionais trouxe um conjunto de parâmetros importantes a respeito da estruturação urbana. Os índices utilizados mostraram, no caso do Distrito Federal, que a cidade é fortemente dependente do sistema viário disperso, que sobremaneira onera o transporte público e que está relacionado à segregação espacial da população. Essa segregação se dá, conforme já relatado, em função de $82 \%$ dos empregos formais encontrarem-se na RA1 (Plano Piloto e entorno imediato) e menos de $10 \%$ da população morar nessa localidade. Também, o alto custo de vida do Distrito Federal faz com que a população de classes média e inferiores procurem habitações cada vez mais distantes do centro, uma vez que o valor delas diminui à medida que se distanciam do CCS.

Esse distanciamento do CCS também implica aumento de custo em infraestrutura, pois as novas cidades e os novos assentamentos, cada vez mais distantes, fazem com que seja necessária a estruturação de longas redes, o que eleva seu custo para a população e para o governo. Dada a vasta e ociosa infraestrutura disponível, passando frequentemente por enormes descontinuidades urbanas, seria bem menos oneroso adensar as cidades do Distrito Federal ou ocupar faixas lindeiras às vias já implantadas, do que criar localidades urbanas do nada - como é infelizmente a regra.

A interação entre o ser humano e a cidade é cada vez mais intensa, sendo ambas afetadas mutuamente. Featherstone (1996) mostra a transformação do comportamento humano em relação às modificações do espaço, e a modificação desse em função de uma nova configuração de sociedade. O autor destaca, por exemplo, que no século XIX, em Paris, havia pessoas que apreciavam o espaço urbano, misturando-se com a ele, sendo conhecidas como flâneurs, que dispunham de seu tempo para caminhar, olhar, entremear-se com os espaços da cidade, sem qualquer preocupação. 
$\mathrm{Na}$ atualidade, apreciar a cidade, como parte dela, de forma a esquecer-se do tempo e do próprio espaço, não é mais possível. O ritmo urbano torna-se cada vez mais rápido, o tempo cada vez mais escasso e a cidade cada vez menos acolhedora. As baixas condições de vida a que foram, e são submetidos os migrantes e as grandes diferenças sociais entre eles e a população urbana, fazem com que com a violência aumente, o que não mais permite o trânsito livre e desprendido de tempo.

O tempo urbano torna-se um novo limitador. A cidade transforma-se, não é mais um espaço público aberto, mas passa a ser formada por diversos espaços privados e fechados. As pessoas não mais circulam, elas transitam em seus carros ou em transportes coletivos, não tendo mais tempo para se ater à forma da cidade.

$\mathrm{O}$ antigo flâneur transforma-se, não sendo mais o circulante dos espaços urbanos públicos, pois se tornou um circulante de espaços fechados e privados, onde principalmente a segurança é que permite o circular. Outra transformação está ligada à interação com o meio, o novo flâneur não interage, apenas absorve uma intensa gama de informações que o meio dispõe.

Outro aspecto presente no Distrito Federal, a demanda por moradia torna-se cada vez maior, em função da baixa oferta de imóveis e do seu alto custo. Uma política perversa de não atendimento a essa demanda acaba por fomentar a ocupação irregular de áreas públicas, o parcelamento de chácaras que são transformadas em condomínios e a invasão de reservas e áreas de proteção ambiental. A moradia para a classe média é escassa ou está a preços muitas vezes inacessíveis, e essa parte da população torna-se o grande alvo dos loteamentos e condomínios irregulares, o que gera novas áreas urbanas. Essas novas áreas, por não terem planejamento adequado, acabam por tornarem-se prejudiciais à natureza, devido aos desmatamentos, impermeabilizações de ruas e acessos e pelo uso indiscriminado de recursos hídricos subterrâneos.

O Plano Piloto, por ser patrimônio histórico da humanidade, acaba por ver engessada a possibilidade de crescimento habitacional, devido a uma visão muito rígida sobre patrimônio, o que faz com que as cidades à sua volta inchem e ampliem seus limites, incluindo em sua área urbana o que anteriormente era área rural. Isso gera consequências socioambientais muito graves, a começar pelo aumento da poluição atmosférica pela emissão de gases poluentes provenientes da grande circulação de veículos.

Os dados gerados a partir do cálculo da dispersão urbana mostraram-se interessantes ao posicionarem as cidades de acordo com sua estruturação e ocupação espacial. Como o conjunto utilizado apresenta cidades com valores extremos (Xangai, 0,78 e Bombaim, 3,08), a escala linear usada para normalização dos dados sofre forte influência desses extremos. Uma possibilidade para trabalhos futuros seria a utilização de escalas logarítmicas que além de linearizar os dados tenderiam a posicioná-los a distâncias mais constantes, o que poderia melhorar a distribuição dos valores dentro da escala. De qualquer forma, devem-se avaliar as limitações e distorções desse método a fim de que sua aplicação seja validada.

As etapas desenvolvidas foram focalizadas para a geração de dados e informações de fácil acesso e que possam vir a fornecer uma percepção mais realista da ci- 
dade. Um aspecto interessante desse método é que ele não está acabado e pode ser continuamente modificado, de forma a representar as mudanças que ocorrem no meio urbano.

A mensuração de características da cidade não deve ser encarada com um processo cansativo, irreal e que só tem interesse para estatísticos. Deve-se buscar mudar essa mentalidade, de forma que os estudiosos, planejadores e gestores urbanos tenham nessa ferramenta um auxílio na tomada de decisões. Como já dito, o conhecimento da espacialização de problemas urbanos é essencial para o direcionamento correto de diversos tipos de provimentos, para uma gestão mais eficiente e que venha a atender, de fato, as demandas prioritárias da população.

O método aqui proposto permite maior transparência às ações governamentais e o acompanhamento das transformações causadas por essas ações. Com o desenvolvimento tecnológico, os Sistemas de Informação Geográfica (SIG) tornam-se mais acessíveis, com o uso cada vez mais disseminado da internet, os webgis ou SIG interativos on-line podem tornar-se ferramentas poderosas de disseminação e acompanhamento das ações dos governos.

Assim, a depender das condições políticas, a população pode ser mais facilmente incluída no processo de tomada de decisões a respeito do espaço onde vive. Seria possível ter-se uma posição da comunidade sobre as prioridades para a resolução dos problemas, escolhendo, por exemplo, entre as alternativas: investir mais em educação, saneamento ou arborização urbana para reduzir o desconforto térmico? Melhorar o transporte público para minorar os efeitos de distância ao trabalho? Criar empregos no local (por estranho que pareça, algumas comunidades preferem viver em vizinhanças exclusivamente residenciais, como é o caso dos habitantes do Lago Sul e Lago Norte)? Essas alternativas poderiam ser identificadas e discutidas com maior clareza e o atendimento à população melhor definido por prioridades estabelecidas de maneira mais compartilhada entre governo e sociedade civil.

\section{Referências bibliográficas}

Bertraud, A. \& Malpezzi, S. (2001). The Spatial Distribution of Population in 35 World Cities: The Role of Markets, Planning, and Topography. Wisconsin-Madison CULER working papers 01-03. University of Wisconsin Center for Urban Land Economic Research. Disponible en www.bus.wisc.edu/realestate/pdf/pdf/Bertaud\%20and\%20Malpezzi\%20Part20One. pdf. Acesso: 27/09/2003.

Bitencourt, L. (2004). Exposição Pessoal a Particulados Atmosféricos no Centro de Taguatinga, DF. Trabalho final de graduação, Universidade Católica de Brasília, Taguatinga, DF, Brasil.

Campos, N. (1998). A segregação planejada. En A. Paviani (Org.), A conquista da cidade (2a ed.). Brasília: Editora Universidade de Brasília.

Clark, D. (1985). Introdução à Geografia Urbana. São Paulo: Difel-Difusão Editorial.

Companhia de Planejamento do Distrito Federal (Codeplan). (2008). Síntese de Informaçóes Socioeconômicas. Brasília, DF: Autor. 
Costa, S. M. F \& Silva, D. C. (2007). Caracterização da dispersão residencial (urban sprawl) utilizando geotecnologias. Florianópolis, SC. Anais do XIII Simpósio Brasileiro de Sensoriamento Remoto, 21-26 abril.

Dâmaso, K. S. (2004). Exposição pessoal a particulados atmosféricos no centro de Brasília, DF. Trabalho final de graduação. Universidade Católica de Brasília, Taguatinga, DF, Brasil.

Departamento Intersindical de Estatística e Estudos Socioeconômicos (DIEESE). (2008). Pequisa de emprego e desemprego no Distrito Federal. Brasília, DF. Disponible en http://www.dieese. org.br/ped/brs/pedbrsAnual2008.pdf. Acesso: 28/04/2010.

Genovez, P. C. (2002). Território e desigualdades: Análise espacial intraurbana no estudo da dinâmica de exclusão/inclusão social no espaço urbano em São José dos Campos - SP. Dissertação de Mestrado, Instituto Nacional de Pesquisa Espacial (INPE), São José dos Campos, SP.

Genovez, P. C., Caetano, N. R. \& Estrada, R. D. (2000). Análise espacial e estatística da metodologia de construção do Índice de Exclusão/Inclusão Social: Relativo à área urbana de São José dos Campos - SP (Censo IBGE 1991). São José dos Campos, SP: Instituto Nacional de Pesquisa Espacial (INPE). Disponible en www.dpi.inpe.br/geopro/exclusao. Acesso: 20/10/2003.

Hasse, J. \& Lathrop, R. G. (2003). A Housing-unit-level approach to characterizing residential sprawl. Photogrammetric Engineering and Remote Sensing, 69(9), 1021-1030.

Hillier, B. and Hanson, J. (1984) The Social Logic of Space. Cambridge: Cambridge University Press. Hillier, B., Penn, A., Hanson, J., Grajewskiet, T., \& Xu, T. (1993). Natural movement: or, configuration and attraction in urban pedestrian movement, Environment and Planning B, 20(1), 29-66.

Holanda, F. (2002). O espaço de exceção. Brasília, DF: Editora Universidade de Brasília.

Holanda, F. (2003). Uma ponte para a urbanidade. En F. Holanda (Org.), Arquitetura \& Urbanidade (Cap. 2). São Paulo, SP: ProEditores Associados Ltda.

Holanda, F., Passos A. M., Cavalcante, A., Simões de Bello, L. R. \& Melasso, P. (2001). Eccentric Brasilia. Proceedings of the Space Syntax - III International Symposium, A. Alfred Taubman College of Architecture and Urban Planning, University of Michigan, Ann Arbor, pp. 531-538.

Instituto Brasileiro de Geografia e Estatística (IBGE). (2002). ESTATCART - Sistema de Recuperação de Informaçôes Georreferenciada. Rio de Janeiro, RJ: Autor. Versão 1.1, CD-ROM.

Instituto Brasileiro de Geografia e Estatística (IBGE). (2010). Disponible en www.ibge.gov.br. Acesso: 26/04/2010.

Instituto Nacional de Estudos e Pesquisas Educacionais Anísio Teixeira (INEP). (2009). Censo da Educação Superior 2008, Dados Preliminares. Resumo Técnico. Brasília: Autor.

Jenks, M. \& Burgess, R. (2000). Compact Cities: Sustainable Urban Forms for Developing Countries. Londres: Spon Press.

Koga, D. (2003). Medida das cidades entre territórios de vida e territórios vividos. São Paulo, SP: Cortez.

Lago, L. C. (2000). O que há de novo na clássica núcleo-periferia: A metrópole do Rio de Janeiro. En L. C. Q. Ribeiro (Org.), O futuro das metrópoles: desigualdades e governabilidade. Rio de Janeiro: FASE, 2000.

Levin, J. \& Fox, J. A. (2004). Estatística para Ciências Humanas (9a ed.). São Paulo, SP: Prentice Hall. Ojima, R. (2007). Análise comparativa da dispersão urbana nas aglomerações urbanas brasileiras: elementos teóricos e metodológicos para o planejamento urbano e ambiental. Tese de Doutora- 
mento, Universidade Estadual de Campinas (UNICAMP), Instituto de Filosofia e Ciências Humanas, Campinas, SP.

Peponis, J. (1989). Espaço, cultura e desenho urbano no modernismo tardio e além dele. Publicación original en Ekistics, 56(334/5), 93-108, traducida por Frederico de Holanda.

Reis, N. G. (2006). Notas sobre urbanização dispersa e novas formas de tecido urbano. São Paulo: Via das Artes.

Ribeiro, R. \& Holanda, F. (2005). Urban Morphology and Thermal Comfort in the Cities. Proceedings of the 5th International Space Syntax Symposium (pp. 355-363). Delft, Holland, 13-17 June.

Ribeiro, R. (2003). Geotecnologia em apoio à aplicação de instrumentos de politica urbana. Dissertação de Mestrado, Universidade de Brasília, Faculdade de Arquitetura e Urbanismo (FAU), Brasília, DF.

Ribeiro, R. (2008). Índice composto de qualidade de vida urbana. Aspectos de configuração espacial, socioeconômicos e ambientais urbanos. Tese de Doutoramento, Universidade de Brasília, Faculdade de Arquitetura e Urbanismo (FAU), Brasília, DF.

Ribeiro, R., Holanda, F., Romero, M., Baptista, G., Bias, E. (2005). O perfil urbano e o comportamento socioeconômico no DF. Proceedings of the Environmental Planning and Management International Congress. Brasília, DF.

Secretaria de Desenvolvimento Urbano e Habitação do Distrito Federal (SEDUH). (2004). Modelo de gestão estratégica do território do Distrito Federal. Brasília: Metroquatro Arquitetura e Tecnologia.

Sposati, A. (2000a). Cidade, território, exclusão/inclusão social. Congresso Internacional de Geoinformação - Geo Brasil. Citado en P. Genovez, Território e desigualdades: análise espacial intraurbana no estudo da dinâmica de exclusão/inclusão social no espaço urbano em São José dos Campos, SP. Dissertação de Mestrado em Sensoriamento Remoto. São José dos Campos: Instituto Nacional de Pesquisas Espaciais (INPE), 2002.

Sposati, A. (2000ba). Mapa da exclusão/inclusão social da cidade de São Paulo: dinâmica social dos anos 90. Citado en P. Genovez, Território e desigualdades: análise espacial intraurbana no estudo da dinâmica de exclusão/inclusão social no espaço urbano em São José dos Campos, SP. Dissertação de Mestrado em Sensoriamento Remoto. São José dos Campos: Instituto Nacional de Pesquisas Espaciais (INPE), 2002. 
